\title{
Recusa Escolar: um Estudo de Caso em Ludoterapia Comportamental
}

Laura dos Santos Gomes Coelho

Universidade de Brasília, DF, Brasil.

\begin{abstract}
Resumo: Recusa Escolar é o termo que refere-se à dificuldade do estudante (criança ou adolescente) em permanecer total ou parcialmente no ambiente escolar, gerando angústia e sofrimento. Ludoterapia comportamental foi utilizada no atendimento de Rita, uma menina (oito anos) que recusava ir à escola. O atendimento consistiu em avaliação (entrevistas e observação) e intervenções (alteração do padrão de brincar e orientações aos pais). Rita apresentou mudanças em termos de complexidade do lúdico e aceitação da escola. Teoria da motivação de Dember e Earl foi utilizada para explicar as escolhas lúdicas na direção hipotetizada; foi discutida a carência de detalhamento sobre a tomada de decisão em ludoterapia comportamental. É sugerido um modelo de tomada de decisão clínica que descreva como o psicólogo analisa as interações da criança com seu ambiente. Tal modelo de tomada de decisão deve ser capaz de incluir as características principais do conceito de lúdico presentes na teoria de Dember-Earl. Palavras-chave: Tomada de Decisão, Recusa Escolar, Ludoterapia Comportamental.
\end{abstract}

\section{School Refusal: a Case Study in Behavioral Play Therapy}

\begin{abstract}
School refusal" is the term that is used to express students (child or adolescent) struggling with staying wholly or partly within the school environment, generating anguish and suffering. Behavioral Play Therapy was used to treat Rita, a girl (8 years old) who refused to go to school. Treatment consisted of assessment (interviews and observation) and interventions (change in the pattern of play and guidelines to parents). Rita showed changes in the complexity of play and agreed to go to school. The Motivation Theory by Dember and Earl was used to explain ludic choices in the hypothesized direction; the lack of details on the decision making in Behavioral Play Therapy was also discussed. A model of clinical decision-making that describes how the psychologist analyzes the child's interactions with his environment is suggested. This decision-making model should be able to include the main features of the concept of play presented by Dember and Earl in their theory.

Keywords: Decision Making, School Refusal, Behavioral Play Therapy.
\end{abstract}




\title{
Rechazo a la Escuela: un Estudio de Caso en Ludoterapia del Comportamiento
}

\begin{abstract}
Resumen: "Rechazo a la escuela" es el término que se utiliza para denotar la dificultad del alumno (niño o adolescente) para permanecer total o parcialmente en el ámbito escolar, generando angustia y sufrimiento. La ludoterapia del comportamiento se utilizó para tratar a Rita, una niña (8 años) que se negaba a ir a la escuela. El tratamiento consistió en una evaluación (entrevistas y observación) y algunas intervenciones (cambio en el patrón de juego y directrices para los padres). La niña mostró un cambio en el nivel de complejidad del juego y aceptó ir a la escuela. La Teoría de la Motivación de Dember y Earl se utilizó para explicar las opciones lúdicas empleadas en la dirección hipotética; se señaló la falta de detalle en la toma de decisiones en ludoterapia del comportamiento. Se sugiere un modelo de toma de decisiones clínicas que describa cómo el psicólogo analiza las interacciones del niño con su entorno. Este modelo de toma de decisiones debe ser capaz de incluir las principales características del concepto de juego presente en la teoría Dember-Earl.

Palabras clave: La Toma de Decisiones, Rechazo a la Escuela, Ludoterapia de Comportamiento.
\end{abstract}

\section{Introdução}

Na ludoterapia comportamental, o lúdico é a dimensão central tanto para a compreensão do comportamento da criança que está em atendimento psicológico quanto para criar intervenções clínicas por meio de jogos, filmes e/ou interações verbais (Coelho, 2001, 2008; Gomes, 1998). As análises teóricas sobre o lúdico elaboradas por Aristóteles (2009) e Tomás de Aquino ressaltam a importância do lúdico para a compreensão do ser humano (Lauand, 2006). Segundo Aristóteles (2009), "a vida também inclui o descanso e uma forma de descanso é o entretenimento proporcionado pela conversação ... o descanso e o entretenimento parecem ser um elemento necessário à vida" (p. 140). Segundo Lauand (2006), Tomás de Aquino concorda com Aristóteles de que há "uma virtude do brincar: a eutrapelia. E há também vícios por excesso e por falta: as brincadeiras ofensivas e inadequadas, por um lado, e, por outro, dureza e a incapacidade de brincar (também um pecado)" (p. 2) e argumenta que, para Tomás de Aquino, o lúdico está associado a uma aprendizagem mais eficiente e menos aborrecida, permitindo a criação de novos conhecimentos e, talvez, esteja na base da criação do mundo por Deus. Segundo Lauand (2006), a proposta de Tomás de Aquino sobre o lúdico vai de encontro à concepção do senso comum e da literatura (por exemplo, no romance "O nome da Rosa", de Umberto Eco) acerca da relevância do lúdico na Idade Média.

Em Psicologia, o lúdico assume papel central na teoria da motivação de Dember-Earl (Dember e Earl, 1957), que procura descrever e explicar como e por que as pessoas reagem a porções do ambiente, por que ocorrem mudanças de atenção momentâneas, por que os estímulos podem ser "convidativos" e procura predizer várias reações das pessoas a estímulos complexos. Na teoria de Dember-Earl, num contexto de comportamento exploratório e de curiosidade, é predito que o indivíduo tende a familiarizar-se com o ambiente investigando aquela parte do ambiente com a qual mantém menos contato sensorial até aquele momento (Dember \& Earl, 1957). A teoria de Dember-Earl se desenvolve em torno de três medidas de complexidade: a complexidade do estímulo, a complexidade do indivíduo e a discrepância entre ambas. A teoria relaciona as medidas de complexidade a medidas de livre escolha. Livre escolha é definida como liberdade do indivíduo em: 1) alternar entre atividades, 2) iniciar e 3) finalizar a atividade quando quiser. As respostas do indivíduo a um grupo de estímulos são assumidas ser mediadas por atributos psicológicos. Tais atributos não são propriedades físicas dos estímulos mas são definidos por meio de procedimentos, sendo o mais comum o de escolha preferencial numa situação de "livre escolha", conforme definida acima, onde são apresentados dois estímulos e o indivíduo escolhe um deles e avalia-os (quão divertidos são, grau de interesse, nível de dificuldade...). A teoria prevê que, na condição de livre escolha, o indivíduo responderá a um estímulo na proporção inversa da diferença entre a complexidade do estímulo e a complexidade do indivíduo mais um incremento.

A Figura ilustra a teoria da motivação de Dember-Earl (Dember \& Earl, 1957). 


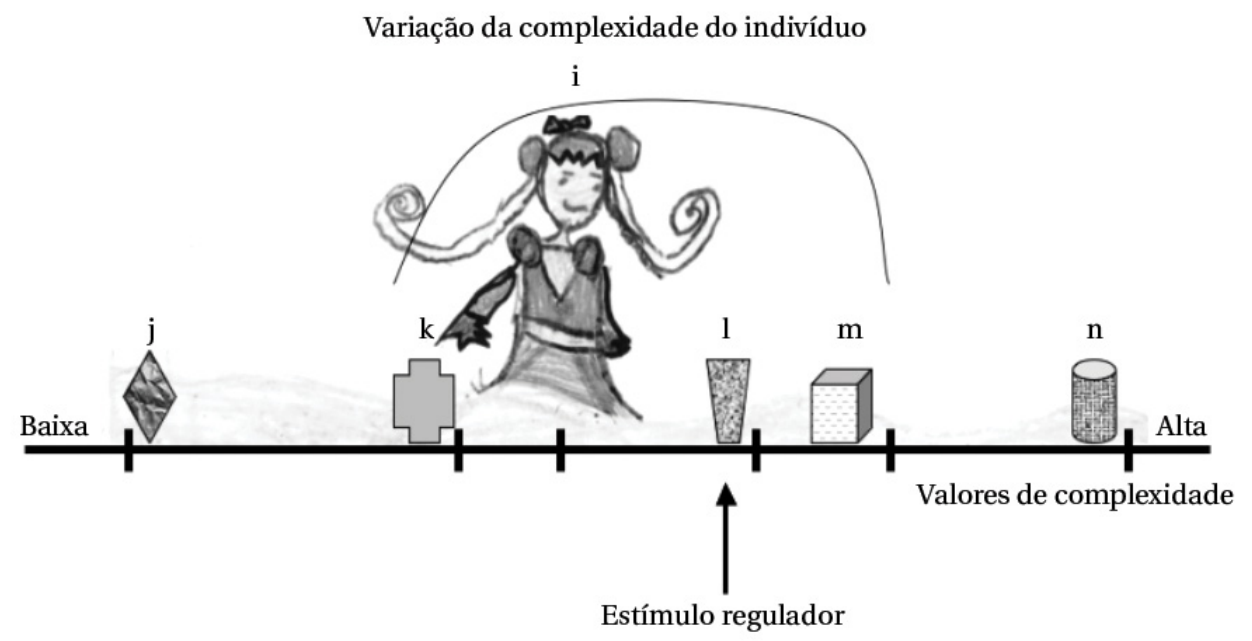

Figura

Representação da teoria da motivação de Dember-Earl, na qual os estímulos e o indivíduo estão num mesmo contínuo de complexidade, que varia entre baix complexidade e alta complexidade. Indivíduo " $i$ " escolhe aqueles estímulos próximos a sua complexidade (no caso, o estímulo " $k$ "). Interação com o estímulo regulador, "l" ou " $m$ ", produz aumento na complexidade do indivíduo até um certo limite (no caso, estímulo " $n$ ").

A teoria prevê que o indivíduo (i) diminuirá a exploração do ambiente somente se os estímulos são muito complexos (estímulo "n", por exemplo) ou se o ideal de complexidade do indivíduo é maior do que os estímulos do ambiente (estímulo “j”, por exemplo). O estímulo com complexidade maior do que o incremento é denominado estímulo regulador ("pacer"). Somente se o indivíduo mantém interação com um determinado estímulo regulador aumentará sua complexidade em relação àquele atributo. À medida que a complexidade do indivíduo aumenta ele responde a estímulos reguladores de maior complexidade (estímulo "m", por exemplo). Por exemplo, considere jogos de quebra-cabeça de 60, 120, 500 peças; o quebra-cabeças de 60 peças representa o estímulo "k", próximo do ideal de complexidade da criança; interação com o quebra-cabeças de 120 peças aumenta a complexidade do indivíduo em relação a este tipo de estímulo, podendo tornar-se estímulo regulador; o quebra-cabeça de 500 peças representa para algumas crianças um jogo muito complexo, um estímulo de "complexidade alta" (o estímulo "n" na Figura). A criança tende a escolher os jogos próximos a sua complexidade. A teoria da motivação de Dember-Earl é aplicável somente no caso de indivíduos não ansiosos, pois ansiedade tende a produzir estereotipia no comportamento de escolha do indivíduo.

Aplicando a teoria de Dember-Earl ao contexto da ludoterapia comportamental, tanto o comporta- mento exploratório quanto o padrão lúdico esperados numa sessão lúdica podem ser afetados pela complexidade dos brinquedos, pelo ideal de complexidade em que se encontra a criança e, principalmente, pela condição de "livre escolha" que caracteriza o ambiente de atendimento em ludoterapia comportamental. Contudo, no contexto clínico, solicitar que a criança sistematicamente faça julgamentos comparativos das atividades lúdicas para se criar a escala de complexidade dos estímulos e do indivíduo pode representar descontinuidade da brincadeira. $\mathrm{O}$ procedimento mais usual é o clínico fazer o registro, num caderno, do comportamento de livre escolha de cada brinquedo ou atividade lúdica realizado pela criança a cada momento ao longo do atendimento. Metodologicamente, faz-se necessário desenvolver modos de julgamentos comparativos mais adequados ao contexto clínico infantil.

Aperfeiçoar a proposta de Dember-Earl sobre lúdico tanto em termos teóricos quanto metodológicos pode produzir atendimento de melhor qualidade às diversas queixas apresentadas pelas crianças no contexto clínico. As queixas mais frequentes no atendimento clínico infantil são demandadas pela escola (Cunha \& Benetti, 2009). Uma das queixas comumente encontrada na escola é o comportamento de recusa escolar (Kearney, 2002). Kearney e Albano (2004) definem recusa escolar como dificuldade da criança ou adolescente de permanecer 
total ou parcialmente no ambiente escolar, gerando angústia e sofrimento. Kearney e Albano (2004) mostram que a recusa escolar totaliza entre $5 \%$ a $28 \%$ das queixas escolares e destacam a heterogeneidade do comportamento de recusa escolar do ponto de vista de problemas internos (depressão, ansiedade, fadiga, medo e queixas psicossomáticas) e externos (agressão verbal e física, abandono, apego e birra).

Segundo Kearney (2002), várias queixas e transtornos mentais estão relacionadas a recusa escolar, o que torna difícil uma classificação; ele propôs como alternativa destacar a função ao invés da forma do comportamento. Na classificação funcional de Kearney (2002), a recusa escolar seria função de: 1) esquiva de estímulos aversivos que provocam afetividade negativa (por exemplo, angústia, ansiedade, depressão); 2) esquiva de estímulos aversivos nos contextos sociais e ou situações de avaliação (apresentações, seminários e ensaios); 3) atenção de pessoas significativas (pais, professores, amigos e familiares) e 4) obtenção de reforço positivo fora do contexto escolar (dormir na casa de amigos, brincar e sair). Os fatores 1) e 2) referem-se ao reforço negativo no contexto escolar e os fatores 3) e 4) referem-se à obtenção de reforço positivo no contexto extraescolar. Kearney e Silverman (1993) desenvolveram a Escala de Avaliação de recusa escolar com versão para pai, mãe e a criança. A escala tipo Likert é composta por 24 itens, 6 itens para cada um dos quatro fatores. Após os membros da família preencherem a escala, calcula-se o escore total para cada um dos fatores. Tendo em vista a variabilidade nas respostas trabalha-se com a média das respostas de pais e criança. Kearney (2002) ressalta o predomínio de publicações sobre o tratamento da recusa escolar em jovens com apenas uma das quatro categorias de recusa escolar.

O presente artigo relata um estudo de caso de recusa escolar de uma criança de oito anos, denominada Rita (todos os nomes citados neste artigo são fictícios); o objetivo do relato de caso é contextualizar a aplicação do conceito de lúdico em ludoterapia comportamental. A publicação do presente relato teve o consentimento da mãe e da própria Rita que, 15 anos após a realização do atendimento, leu o presente relato e teve acesso ao caderno com os registros das sessões e os autoregistros que ela própria fizera sobre a escola.

\section{Rita}

Rita, oito anos, morava com os pais (Sara e João), os dois irmãos de 19 e 17 anos e uma prima de 14 anos, cursava o $2^{\circ}$ ano numa escola da rede privada do DF. Rita gostava de ir para chácara onde brincava com os animais, raramente assistia televisão e não gostava de bonecas; as atividades lúdicas preferidas eram peteca, futebol com os irmãos, teclado e palavras-cruzadas. Em casa, gostava de assistir televisão; familiares consideravam-na excelente companhia para ver tv, meiga, carinhosa, esperta, amiga, gostava de conversar com os pais, obedecia aos comandos das atividades de vida diária, era tímida no contexto extrafamiliar, não gostava de sair de casa, participava somente das festas de família e conseguia seus objetivos pela insistência. Rita recusava-se a usar óculos porque achava feio, os colegas sorriam por ela estar usando óculos (apesar da professora proibir essas manifestações) e, quando usava os óculos, sentia intensa dor de cabeça. Rita explicou ao oftalmologista sobre as ocorrências das dores, mas ele justificava que era necessário usar e que a recusa de Rita implicaria no agravamento da sua dificuldade visual.

\section{Histórico da recusa escolar}

Rita viveu em uma chácara até quatro anos de idade interagindo somente com adultos. No período em que morou na chácara, Rita jogava peteca e futebol com os irmãos e gostava de brincar com animais da chácara. Após a mudança para o apartamento na cidade apresenta redução no padrão lúdico (brincava de palavras-cruzadas, por exemplo). No primeiro ano da pré-escola (1991), aos quatro anos de idade, a família mudou-se da chácara para um apartamento em Brasília. Ela recebia atenção de todos da família, principalmente da prima que favorecia a aproximação com outras crianças. Rita reclamava quando não recebia atenção das colegas do bloco onde morava; não gostou da escola, faltando durante aproximadamente 30 dias; no ano seguinte, transferiu-se de escola no segundo semestre, tinha muitas faltas e não gostava de estudar, mas em casa era autônoma e executava todos os deveres de casa. Em 1993, na escola da rede oficial, começou a relatar dores nas pernas, cabeça e garganta. A dor de cabeça permaneceu até o fim do ano. Em agosto de 1993, a prima que morava com eles mudou-se de Brasília. Segundo os pais, todos os familiares sentiram falta dela mas Rita sofreu mais porque estudavam juntas; a prima era atenciosa e estabele- 
cia o contato de Rita com outras crianças do prédio. Em 1994, Rita foi transferida para um colégio da rede privada em período integral. Rita reclamava que estudava muito e não gostava de ficar na escola no período integral. No ano de 1995, ela não apresentava contato social e estava perdendo a habilidade social que tinha adquirido e era necessário que os familiares a obrigassem a fazer os deveres de casa que antes executava espontaneamente; recusava-se a ir para a escola; chorava, trancava-se no quarto e escondia-se embaixo da cama; as notas nas provas, nesse período, eram altas (entre 9 e 10). Nos quatro anos de escolarização, Rita apresentou dificuldade de ir à escola; chorava e pedia para não ir mais. Na época do atendimento, estava há dois anos na mesma escola, estudando somente em um turno. Ela negava-se a participar das festas da escola e Sara a buscava antes do horário das festas. Todas as professoras de Rita elogiavam sua capacidade de aprender rápido e fornecer as respostas antes de concluir a explicação.

A sugestão para a psicoterapia foi de uma amiga da mãe e do médico que consideravam Rita amadurecida para a idade de oito anos. Rita gostou e aceitou a ideia de ir a uma psicóloga porque acreditava que no consultório receberia uma "poção mágica" para não precisar ir à escola. A psicóloga do departamento médico da empresa onde Sara trabalhava encaminhou Rita para atendimento psicológico e sugeriu que a causa dessa dificuldade poderia ser desmotivação. A mãe desabafou que o atendimento psicológico seria a última alternativa, pois não sabia mais como lidar com a filha. A entrevista inicial foi realizada somente com a mãe porque João, aposentado, apesar de ser favorável ao atendimento preferia ficar em casa. O psicodiagnóstico consistiu em: 1) entrevista inicial com a mãe; 2) uma visita à escola com observação; 3) duas sessões lúdicas com Rita; 4) uma sessão de entrega do laudo psicológico e 5) um contato telefônico com a coordenadora da escola. $\mathrm{O}$ atendimento completo foi realizado no período de 26 de junho a 27 de novembro de 1995.

\section{Psicodiagnóstico (ou "por que Rita não brinca?")}

Baseando-se na estrutura de atendimento em ludoterapia comportamental apresentada nos estudos de casos relatados por Gomes (1998) e Coelho (2001; 2008), o psicodiagnóstico foi realizado a partir de informações de diversos contextos (entrevista com pais, entrevista com cuidadores, contato com especialistas que avaliaram a criança, visita à escola, sessões lúdicas com a criança, visita à casa, uso de instrumentos de questionário, escalas de avaliação psicológica, observação naturalística e auto-registro). Excepcionalmente, não foram realizadas filmagens nem aplicado testes psicométricos. O psicodiagnóstico produziu as seguintes categorias de observação:

A categoria "interação social reduzida" foi hipotetizada após a observação do comportamento em sala de aula, visita à escola, entrevista com a coordenadora e sessões lúdicas com Rita e é exemplificada por Rita: 1) permanecer quieta na sala de aula; 2) ficar sozinha no recreio; 3) pouca participação nas atividades sociais da escola; 4) não apresentar iniciativa em conversar com os colegas e 5) chorar e recusar-se a participar das festas escolares. Em termos de desenvolvimento infantil espera-se que aos oito anos uma criança interaja com seus pares em jogos de regras, atividades lúdicas livres com os pares e interação social em diversos ambientes (escolar, social e familiar). Dificuldade ou limitação na interação social pode afetar o desenvolvimento psicossocial da criança.

A categoria "comportamento exploratório limitado" foi hipotetizada após as duas primeiras sessões lúdicas de Psicodiagnóstico e é exemplificada por Rita mostrar reduzida exploração a sala, pegar, inspecionar e comparar os brinquedos na sala lúdica com brinquedos variados e de diferentes faixas etárias. Por exemplo, na primeira sessão, Rita entrou sozinha na sala lúdica, observou rapidamente a sala e a terapeuta e, por fim, sentou-se na cadeira e dialogou com a terapeuta sem explorar os brinquedos da sala.

A categoria de observação "padrão lúdico limitado" foi hipotetizada após as duas sessões lúdicas de psicodiagnóstico (Tabela) e da entrevista inicial com a mãe e refere-se ao fato de Rita não demonstrar interesse em selecionar jogos no consultório (nas sessões lúdicas foi solicitado que ela escolhesse algum brinquedo ou jogo e ela verbalizou que não gostava de brincar, não selecionou brinquedos ou jogos e a interação foi exclusivamente verbal) e em outros contextos (escolar e em casa). As categorias de observação "padrão lúdico limitado" e "comportamento exploratório limitado" se referem a características da atividade lúdica. A diferença entre estas categorias é que o comportamento exploratório antecede ao brincar propriamente dito e fornece informação sobre as- 
pectos do padrão lúdico da criança: diversificado ou estereotipado, criativo ou repetitivo.

A categoria de observação "habilidade argumentativa” refere-se à capacidade de Rita nos seguintes contextos: 1) na interação dialógica, apresentava vocabulário complexo e diversificado; 2) na interação familiar, comentava as notícias dos jornais e emitia opiniões sobre política e economia dos pais; e 3) utilizava argumentos para expressar e justificava seus argumentos quando expressava suas ideias. Por exemplo, Rita definiu a função do psicólogo como a pessoa que ajudava as pessoas a resolverem seus problemas e, a seguir, perguntou se a psicóloga poderia ajuda-lá a não frequentar a escola justificando que não gostava da escola porque sentia dores de cabeça, dores abdominais e gostava de ficar em casa.
A categoria de observação "seriedade" refere-se ao fato de Rita apresentar, em duas sessões, expressão facial sem sorrisos, sobrancelhas arqueadas e testa franzida. Por exemplo, nas sessões lúdicas, Rita permanecia séria e a postura corporal era tensa, vestia-se como adulta com camisas sociais e calça comprida de cores escuras, cabelo preso e sapato fechado.

Em relação a aspectos psicossomáticos, tanto na entrevista quanto no contato telefônico e visita à escola foi relatada queixa de dores de cabeça, nas pernas e na garganta. Rita reclamou em duas sessões lúdicas de dores, do nervosismo, insônia e, ao chegar na escola, de dor no estômago e irritabilidade. Em resumo, os aspectos mais relevantes do psicodiagnóstico foram a interação social e lúdica reduzidas que Rita mantinha com os colegas da escola e a "seriedade" na interação escolar; a habilidade argumentativa de

Tabela

Duração (em minutos) de cada atividade (numeral entre parêntese) realizada por Rita em cada sessão de atendimento conforme o nivel e complexidade inferior (-) ou superior (+) a complexidade ideal de Rita.

\begin{tabular}{|c|c|c|c|c|}
\hline Sessão & Atividade & - & $\begin{array}{l}\text { Complexidade } \\
\text { ideal de Rita }\end{array}$ & + \\
\hline Psicodiagnóstico 1 & Diálogo (1) & - & $50(1)$ & - \\
\hline Psicodiagnóstico 2 & Diálogo (1) & - & $50(1)$ & - \\
\hline Intervenção 3 & Diálogo (1) e Banco Imobiliário (2) & - & $45(1)$ & $45(2)$ \\
\hline Intervenção 4 & Diálogo (1) e Banco Imobiliário (2) & - & $45(1)$ & $45(2)$ \\
\hline Intervenção 5 & $\begin{array}{l}\text { Jogo da memória (3), Dominó (4), Banco } \\
\text { Imobiliário (2) e diálogo (1) }\end{array}$ & $\begin{array}{l}10(3) \\
\mathrm{e}(4)\end{array}$ & $10(1)$ & $35(2)$ \\
\hline Intervenção 6 & Diálogo (1) & - & $60(1)$ & - \\
\hline Intervenção 7 & Pintura em tela (5) e diálogo (1) & $40(5)$ & $10(1)$ & - \\
\hline Intervenção 8 & Passa ou Repassa (6) e diálogo (1) & - & $20(1)$ & $30(6)$ \\
\hline Intervenção 9 & Passa ou Repassa (6) & - & - & $60(6)$ \\
\hline Intervenção 10 & Banco Imobiliário (2) e exploração dos brinquedos (7) & - & $7(7)$ & $43(2)$ \\
\hline Intervenção 11 & Jogo da Vida (8) e exploração dos brinquedos (7) & - & $5(7)$ & - \\
\hline Intervenção 12 & Passa ou Repassa (6) & - & $5(1)$ & $55(6)$ \\
\hline Intervenção 13 & Banco Imobiliário (2) & - & - & $50(2)$ \\
\hline Alta 14 & Passa ou Repassa (6) & - & - & $60(6)$ \\
\hline Alta 15 & Passa ou Repassa (6) e Jogo da Vida (8) & - & - & 40 (6) e $15(8)$ \\
\hline Alta 16 & Banco Imobiliário (2) & - & $5(1)$ & $45(2)$ \\
\hline Alta 17 & Jogo da Vida (8) & - & $5(1)$ & $55(8)$ \\
\hline Alta 18 & Passa ou Repassa (6) & - & $5(1)$ & $55(6)$ \\
\hline
\end{tabular}


Rita e aspectos psicossomáticos foram considerados de menor relevância para o atendimento. A questão central de investigação do atendimento foi explicar por que Rita não brincava em diversos contextos (escola, casa, consultório)?

\section{Tomada de decisão decorrente do psicodiagnóstico}

Na sessão de entrega do psicodiagnóstico para os pais foi sugerido que Rita fosse atendida em ludoterapia comportamental, por um período de seis meses, com o objetivo de: 1) treino de habilidade social através do lúdico; 2) modelagem/aprendizagem vicária; e3) observações no contexto escolar e entrevistas com a professora e orientadora pedagógica. Foi indicado para os pais sessões de orientação, por um período de seis meses, com objetivo de: 1) orientar aos pais como proceder com Rita na questão da habilidade social, 2) ouvir os pais nas dúvidas e questões sobre os comportamentos de Rita e 3) avaliar a evolução do atendimento. A mãe mostrou-se satisfeita com o laudo e ficou surpresa com a filha, pois, apesar de reclamar da escola e resistir a ir, percebeu que estava aceitando melhor a escola e gostou do atendimento psicológico. Perguntava como tinha sido a sessão e Rita respondia "foi boa, mas não vou te contar nada".

\section{Intervenções em ludoterapia comportamental}

Após a entrega do psicodiagnóstico iniciaram-se as sessões de intervenção totalizando: 16 sessões lúdicas com Rita, oito sessões de orientação aos pais, cinco ligações telefônicas de Rita para a terapeuta, três visitas à escola e uma visita à casa de Rita. $\mathrm{O}$ atendimento durante a intervenção pode ser dividido em três questões de acordo com o tipo de pergunta que se pretendia responder, a saber: "por que Rita não brinca?" "como promover a socialização de Rita a escola?" e "quais os indícios para alta terapêutica?".

A Tabela mostra a duração das brincadeiras e diálogo entre Rita e a psicóloga em cada sessão de atendimento. Observa-se que, nas primeiras duas sessões do psicodiagnóstico, Rita apenas manteve interação verbal sobre a escola e o comportamento de recusa escolar. A partir da terceira sessão, a psicóloga sinalizou que poderia escolher o jogo que quisesse e continuariam conversando, Rita conhecia e brincava em casa com seus familiares, o "Banco Imobiliário". A seguir, brincou uma vez de pintura, dominó e jogo da memó- ria e, ao longo das demais sessões de atendimento, alternou entre os jogos "Banco Imobiliário", "Passa ou Repassa" e "Jogo da Vida" diminuindo progressivamente a interação verbal sobre outros assuntos. De acordo com a teoria de Dember-Earl, o jogo "Banco Imobiliário" seria o "pacer" ou estímulo regulador. Ao explorar ou interagir com o "estímulo regulador" nas duas sessões lúdicas, Rita aumentou sua complexidade em relação àquele atributo do jogo. À medida que a complexidade de Rita aumentou ela respondeu aos estímulos de maior complexidade ("Passa ou Repassa" e "Jogo da Vida", por exemplo, foram jogados pela primeira vez no consultório) em detrimento daqueles de menor complexidade (pintura, jogo da memória e dominó). Rita não retornou ao jogos de menor complexidade (em relação ao ideal de complexidade dela) e que são comumente compartilhados por crianças de sua faixa etária e que já eram conhecidos por Rita. A mudança no padrão de brincar de Rita ocorreu no sentido de preferir jogos mais complexos conforme previsto pela teoria de Dember-Earl.

\section{1 a questão: "por que Rita não brinca?"}

A primeira questão, denominada "Por que Rita não brinca?”, foi investigada na $3^{a}$, $4^{\text {a }}$ e $5^{a}$ sessões, quatro sessões de orientação aos pais (da $1^{\mathrm{a}}$ à $4^{\mathrm{a}}$ ), três contatos telefônicos de Rita para a terapeuta e uma visita à casa de Rita. Nesse período, observou-se mudança acentuada de humor de Rita (expressão sorridente) e início de atividade lúdica. Essas sessões foram duplas com duração de 1 hora e meia; Rita limitou-se a escolher o jogo que lhe era familiar (Banco Imobiliário) porque provavelmente este é o jogo de sua complexidade “ideal”; nessas sessões, Rita permaneceu de 45 a 55 minutos no jogo e o restante do tempo a interação era verbal sem atividade lúdica.

As quatro sessões de orientação abordaram os seguintes temas: 1) estímulo ao brincar ( $1^{\text {a }}$ sessão): os pais seguiam as orientações para incentivar o brincar de Rita e ela começou a recusar a frequentar a chácara nos fins de semana; 2) esquiva esco$\operatorname{lar}\left(2^{\mathrm{a}}\right.$ e $3^{\mathrm{a}}$ sessões): Rita recusava ir à escola, por exemplo: Rita gostava da terapia, mas verbalizou para a mãe: "não adianta ir lá na Laura queria ir lá para arranjar jeito de não ir mais ao colégio, já que não tem jeito...”. Rita não quis ir à aula no primeiro dia, se aborreceu, Rita estava desarrumada e despenteada, a mãe exigiu que ela se arrumasse e Rita a confrontou. Sara explicou para a filha que tinha 
prazo de trinta dias para resolver a questão da escola e que se ela insistisse em recusar ir a escola, perderia a amizade da terapeuta e ela não a levaria mais à terapia; a partir dessa briga, Rita não reclamou mais. A terapeuta esclareceu que é comum que a criança, quando inicia na escola, apresente resistência em separar-se dos pais e a adaptação ao colégio pode tornar-se mais difícil no decorrer dos anos. Rita, nesses quatro anos, internalizou que não gostava do colégio e um dos objetivos do atendimento foi realizar essa adaptação à escola. Rita priorizava as verbalizações negativas sobre o colégio e um dos objetivos da terapia era Rita aprender a brincar, tornar-se mais criança, lúdica, pois desempenhava o papel de uma menina muito séria, com preocupações do mundo adulto; 3 ) verbalização sobre o brincar e interação social limitada ( $1^{\mathrm{a}}$ e $\left.4^{\mathrm{a}}\right)$ : Rita verbalizava que queria morrer pois era criança e não podia brincar, passear e sair; era obrigada a ir para a escola. As verbalizações sobre brincar e passear são indicadores de que, provavelmente, Rita estava começando a considerar interessante brincar e consequentemente preparava-se para aproximação das meninas da sua idade; 4$)$ psicossomática ( $1^{\mathrm{a}} \mathrm{e}$ $2^{\mathrm{a}}$ sessões): Rita sistematicamente telefonava da escola queixando-se de dores de cabeça e, quando era possível buscá-la, no trajeto para casa as dores cessavam. Sara orientava que conversasse com a professora e orientadora, mas ela se recusava. A mãe brigava com a filha e interpretava as dores como "chantagem". Foi solicitado que investigasse sobre as dores de cabeça, como por exemplo, o que estava fazendo quando a dor iniciou, se consumiu algum alimento antes das dores, qual era a localização da dor e se as dores eram contínuas ou intermitentes. O objetivo era que a mãe realizasse o registro do comportamento da filha relacionando quais eventos estavam associados ao relato da filha; 5) a questão "genético x ambiente" ( $3^{\mathrm{a}}$ e $4^{\mathrm{a}}$ sessão): Sara acreditava que a recusa de Rita era de fundo genético e receava que Rita tivesse herdado o comportamento de não gostar de estudar. A proposta da terapeuta não era descartar a hipótese genética, mas de ressaltar a possibilidade de uma mudança de comportamento através de orientações específicas para os pais, a escola e a mediação lúdica com Rita. As informações que Sara fornecia eram todas levadas em consideração e havia cuidado para que não se sentisse confrontada pela terapeuta. O relacionamento so- cial de Rita com as crianças era prioritário, pois esperava-se vínculos afetivos favorecendo amizades para que pudesse generalizar para outros contextos. As verbalizações sobre o brincar indicam que o caso se configurava numa transição do não brincar para o brincar. Nessa fase do atendimento, a tomada de decisão foi visitar a casa, pois deveria haver algo extremamente recompensador para que Rita quisesse permanecer em casa, fortalecendo a esquiva escolar e a interação social limitada.

A visita a casa possibilitou que a terapeuta observasse o ambiente familiar e a interação de Rita com o pai. Rita estava motivada com a visita da terapeuta, mostrou os cômodos da casa e fotos. O pai assistia e conversava sobre o telejornal com a filha que comentava com desembaraço as suas opiniões. O pai fazia perguntas para que a filha pudesse argumentar com maior riqueza de detalhes e elaborar seus comentários. Rita emitia suas opiniões e era valorizada pelos seus pensamentos. Observou-se que o vínculo de pai e filha era muito afetuoso. A visita a casa trouxe uma informação nova: Rita mantinha um padrão de interação verbal com o pai muito sofisticado, mais próximo de um padrão de comunicação típico de adulto; provavelmente, a recusa escolar estava associada ao fato de que nem os colegas nem os professores tinham um padrão de comunicação que Rita estava habituada a ter com o pai e demais familiares.

O vínculo terapeuta-cliente foi significativo o suficiente para que Rita aceitasse as atividades lúdicas gradativamente e começasse a imitar a terapeuta. Provavelmente, a imitação ocorreu por uma série de fatores, tais como interesse, motivação e sentir-se confortável com o contexto lúdico. A imitação da forma como terapeuta interagia nas sessões com tom de voz, as verbalizações durante o jogo. A exploração da sala lúdica e brinquedos ocorreu nas $11^{\mathrm{a}}, 12^{\mathrm{a}}$ e $13^{\mathrm{a}}$ sessões lúdicas onde Rita apresentou iniciativa para explorar os armários, brincou com pintura, colagem, dominó, jogos de tabuleiro, adivinhação e manteve diálogo. Associada à exploração da sala lúdica, iniciou uma diversificação da seleção de jogos. Na sessão 7, manteve somente a interação verbal. Na sessão 8 , sugeriu-se atividade de pintura, nas sessões 9 e 10, iniciou o brincar e conversar simultaneamente. A partir da sessão 9, gradualmente ela escolheu jogos mais complexos ("pacers", na teoria de Dember-Earl) que envolviam interação verbal ou habilidade motora como forma 
de instigar a complexidade para explorar novos tipos de jogos; no decorrer das sessões, Rita preferiu jogos que envolviam interação verbal (Jogo da Vida, Passa ou Repassa, Banco Imobiliário) em detrimento a jogos mnemônicos e de habilidade motora (escolheu apenas uma vez memória e pintura). Tal padrão lúdico está de acordo com o previsto pela teoria da escolha de Dember-Earl.

\section{$2^{a}$ questão: como promover a socialização de Rita na escola?}

A segunda questão compreendeu uma visita a casa, sete sessões lúdicas (da $7^{\text {a }}$ a $13^{\mathrm{a}}$ sessão), duas sessões de orientação aos pais ( $5^{\mathrm{a}}$ e $6^{\mathrm{a}}$ sessão), duas ligações telefônicas de Rita para a terapeuta, e duas visitas a escola, e caracterizou-se pela interação positiva social de Rita por meio da amizade com colega da escola e a interação mais cordial na escola.

Observou-se redução da esquiva escolar na $8^{a}$ sessão; Rita verbalizou que "o colégio não é tão chato". Apesar da redução da esquiva, Rita comemorou uma viagem familiar que proporcionou faltar quatro dias de aula e comentou que gostou da viagem porque conheceu e brincou com primos e outras crianças do bairro. Na $10^{\text {a }}$ sessão, Rita demonstrou bom humor: 1) durante o jogo sorria e fazia brincadeiras verbais com a terapeuta; 2) relatou que queria brincar; 3 ) ambas compartilharam, cooperaram nos jogos e atividades lúdicas e solicitaram ajuda uma à outra; e 4) Rita sorriu, cantou e falou melodiosamente durante os jogos. Observou-se modificação na autoimagem: na 9a, $10^{\mathrm{a}}$ e $11^{\mathrm{a}}$ sessões lúdicas, Rita modificou o penteado e as roupas, vestiu-se com blusas coloridas, saia, tamanco e o cabelo solto.

A coordenadora da escola, na primeira visita a escola, ressaltou que Rita estava mais cordata e a interação com as colegas estava sendo construída gradativamente. Na segunda visita à escola: 1) o professor de informática caracterizou Rita como quieta e que realizava todos os exercícios solicitados; 2) a professora regente destacou que Rita estava muito diferente, interagindo com os colegas, mais participativa nas aulas, demonstrando afetividade, sorrindo e escrevendo bilhetes para ela com termos "adoro você!". Observou-se, na aula de informática, que Rita 1) apresentou a terapeuta a Bárbara, colega que a convidou para brincar na casa dela; 2) as duas contavam sorridentes que dormiriam uma na casa da outra em dias alternados e que fariam passeios;
3) no recreio, Rita conversou com várias colegas, sorriu e observava sorrindo para a terapeuta; e 4) na sala de aula, Rita realizou as tarefas e conversou com Bárbara após término dos exercícios.

Orientação aos pais enfatizou: 1) autonomia pessoal ( $4^{\mathrm{a}}$ e $5^{\mathrm{a}}$ sessão): isto é, incentivar Rita a estar pronta com o uniforme, com o cabelo, o banho e vestir-se para ir à escola. Por exemplo, Sara ficou surpresa ao chegar em casa e encontrar Rita arrumada, pronta para ir à escola; elogiou Rita que sorriu e Sara percebeu Rita penteando mais o cabelo e começou a elogia-lá com o cuidado com o cabelo. A terapeuta enfatizou a excelente conduta de Sara de valorização da autonomia de Rita e o interesse de cuidar da aparência pessoal. Sara ressaltou que estava muito satisfeita com a terapia e que Bárbara estava ajudando muito e sempre estão juntas brincando uma na casa da outra. Bárbara a convidou várias vezes para brincar e dormir na casa dela, a atitude deles foi não permitir e Rita iniciou a recusa de frequentar a chácara. A terapeuta orientou que permitisse Rita dormir na casa da colega e sugeriu que convidassem a colega para brincar e dormir na casa deles.

Em relação ao padrão lúdico, observou-se que Rita respondeu aos estímulos de maior complexidade ("Passa ou Repassa" e "Jogo da Vida", por exemplo, foram jogados pela primeira vez no consultório) em detrimento daqueles de menor complexidade (pintura, jogo da memória e dominó) e que são comumente compartilhados por crianças de sua faixa etária e que eram conhecidos por Rita. A mudança no padrão de brincar de Rita ocorreu no sentido de preferir jogos mais complexos conforme previsto pela teoria de Dember-Earl.

\section{3a Questão: quais os indícios para alta terapêutica?}

Alta terapêutica foi iniciada a partir de duas sessões de orientações aos pais ( $7^{\mathrm{a}}$ e $8^{\mathrm{a}}$ sessões), caracterizada por relato de mudança positiva de humor percebida pelos familiares e frequência a escola sem apresentar comportamento de recusa. A finalização do atendimento clínico foi realizada durante cinco sessões lúdicas (da $14^{\mathrm{a}}$ a $18^{\mathrm{a}}$ sessão) com Rita e caracterizada por interação social positiva, continuidade na escola e redução da recusa escolar, frequência à escola e lúdico espontâneo na sessão de atendimento. 
Na 14a sessão, Rita chegou com o pai, selecionou o Banco Imobiliário e, enquanto jogava, conversava com a terapeuta. Durante o jogo, Rita relatou que ficara sem conversar duas semanas com Bárbara. A $14^{\text {a }}$ sessão, foi a $1^{\text {a }}$ é única que o pai acompanhou Rita ao consultório e, no final da sessão, ele comentou com a terapeuta que Rita não reclamou mais da escola, dos primos e das viagens que antes recusava realizar; e que estava brincando com os primos e os amigos. Os amigos comentavam que Rita estava mais bem-humorada.

Nas $14^{\mathrm{a}}$ e $15^{\mathrm{a}}$ sessão, Rita explicitou que somente queria brincar com os jogos. Foi a primeira vez que ela brincou espontaneamente e de modo relaxado no consultório. Nas sessões 16 a 18, Rita selecionou jogos enquanto, simultaneamente, conversava sorria e chamava atenção da terapeuta para as roupas que estava vestindo. Na $16^{\text {a }}$ sessão, Rita disse que fez várias amigas e retornou à amizade com Bárbara. Brincou espontaneamente com os jogos disponíveis. Na última sessão de atendimento (18 ${ }^{\mathrm{a}}$ sessão), Rita anunciou que estava com uma calça nova pink. A terapeuta a elogiou e brincaram de quente ou frio (a terapeuta escondeu uma lembrança para que Rita encontrasse na sala); Rita disse que decidira continuar no colégio. Foram abordadas questões relativas às férias, evolução do atendimento terapêutico e a continuidade na escola.

Terapeuta orientou aos pais para que atentassem a recaídas e quebra da interação social. Na $7^{\text {a }}$ sessão, Sara disse que apesar de Rita continuar frequentando a escola, preocupava-se com a briga de Rita com Bárbara e a possível repercussão na adaptação à escola. Contudo, apesar do desentendimento entre ambas, Rita aumentou o número de colegas e sentia-se mais confortável na escola. A terapeuta destacou o cuidado da família de não supervalorizar esse evento e que situações similares de términos de amizade são naturais que ocorram no desenvolvimento pessoal.

\section{Acompanhamento}

O acompanhamento foi realizado por telefone no ano seguinte no mês de março de 1996, Sara relatou que estava bem e que às vezes Rita falava do atendimento. Terapeuta destacou que, se os pais e Rita sentissem a necessidade para retorno, poderiam entrar em contato. Após 15 anos da realização do atendimento clínico, Rita relatou que continuou não gostando da escola; terminou o $2^{\circ}$ grau com 17 anos e iniciou três cursos de nível superior, sendo dois deles em universidades concorridas e realizou dois sonhos: viajou para exterior e ficou grávida (estava no oitavo mês). Ressaltou que gostava de ir ao consultório e que brincava; anos mais tarde entendeu que era uma terapia e ainda mantinha guardado o cofre que a terapeuta havia lhe dado.

\section{Discussão}

Kearney (2002) ressalta o predomínio de publicações sobre o tratamento da recusa escolar em jovens com apenas uma das quatro categorias da tipologia de recusa escolar. O presente estudo de caso é o primeiro na literatura sobre recusa escolar a registrar a ocorrência de três das quatro categorias da tipologia de Kearney (2002). A avaliação em ludoterapia comportamental sugeriu que o comportamento de recusa escolar de Rita foi ocasionada por uma inabilidade social de Rita em lidar com os colegas na escola; ela mostrou desinteresse pela escola e, posteriormente, apresentou o quadro de recusa escolar que pode ser descrito pela classificação de Kearney e Albano (2004) do seguinte modo: 1) esquiva de estímulos aversivos que provocam afetividade negativa (por exemplo, reações psicossomáticas de Rita que antecediam as idas a escola, a partir de 6 anos de idade); 2) esquiva de estímulos aversivos nos contextos sociais e ou situações de avaliação (Rita reclamava de ter que realizar apresentações ou atividades coletivas na escola); 3) obtenção de reforço positivo fora do contexto escolar (ficar em casa conversando com o pai aposentado). Provavelmente, este achado decorre dos diversos contextos representativos da vida da criança que a ludoterapia comportamental obtém informações. Escalas psicométricas e questionários de avaliação de recusa escolar precisam ser analisados em comparação com observação, entrevistas com diversos profissionais e familiares para que não se subdimensione o fenômeno de recusa escolar.

O padrão lúdico de Rita na escolha de brinquedos foi descrito pela teoria da motivação de Dember-Earl quando Rita escolheu as brincadeiras próximas a sua complexidade (no caso, as atividades lúdicas verbais). Interação com outros jogos (estímulo regulador) possibilitou que Rita aumentasse seu nível de complexidade. A proposta conceitual de Dember-Earl para analisar o lúdico no 
presente estudo de caso é a de que ao invés de se perguntar "o que é lúdico?" ou "o que há em comum entre os diversos tipos de jogos e brincadeiras utilizadas no consultório?" o ludoterapeuta deveria perguntar "quando uma situação ou contexto torna-se lúdico para uma determinada pessoa?”. Na perspectiva da ludoterapia comportamental, uma situação torna-se lúdica se há uma condição livre escolha, isto é, possibilidade do indivíduo: 1) alternar entre atividades disponíveis na situação, 2) iniciar e 3) finalizar as atividades quando quiser). As três condições de livre escolha permitem ao ludoterapeuta comportamental criar um contexto lúdico desde a primeira sessão ao permitir que a criança possa: 1) iniciar, 2) parar momentânea ou definitivamente a atividade, 3) alternar entre os brinquedos e/ou atividades. Contudo, a proposta de Dember-Earl não captura um aspecto essencial do lúdico infantil: integração de brinquedos e/ou jogos diferentes conforme interesse ou algum atributo ou "peso" psicológico que a criança atribua ao brinquedo (a criança pode, por exemplo, criar uma hierarquia ou organização específica para brincar com bonecos de tamanhos ou de materiais diferentes).

O fato de obter múltiplas informações de diversos contextos corre-se o risco de falha nas seguintes etapas da análise funcional: 1) organização das informações do caso clínico adequadamente, 2) descricão do processo decisório entre as hipóteses alternativas relacionadas ao caso clínico, 3) explicitar quais os pesos foram atribuídos às informações utilizadas na avaliação clínica e 4) comparar adequadamente as hipóteses explicativas do comportamento. Por exemplo, foram descartadas as hipóteses alternativas de desmotivação escolar, altas habilidades e fobia escolar como fatores explicativos do comportamento de recusa escolar e priorizada a limitação em termos de habilidade social e lúdica de Rita. Embora tal decisão tenha se baseado em aspectos relevantes da vida da criança (observação em casa e na escola, entrevistas com familiares e professores), como evitar um viés na avaliação psicológica tal que o ludoterapeuta comportamental ignore ou subdimensione outras dimensões da vida humana e valorize excessivamente o brincar no psicodiagnóstico e nas intervenções? É preciso um tipo de análise funcional que auxilie o clínico a interpretar os "pesos" dos quatro fatores da Escala de Kearney com outras informações obtidas pelo clínico. Por exemplo, utilizar a Escala de Kearney de recusa escolar como um instrumento auxiliar à investigação clínica é preciso especificar como integrar o desempenho na Escala com outras informações (contextuais, clínicas...). Respostas a estas questões auxiliariam o ludoterapeuta comportamental na descrição mais detalhada da interação do indivíduo e o ambiente.

O presente estudo de caso sugere: 1) a teoria da motivação de Dember-Earl como adequada para explicar as escolhas da criança em atendimento em ludoterapia comportamental e 2) a ocorrência do primeiro caso utilizando 3 das 4 categorias da tipologia de Kearney. O desafio que se faz necessário é criar um modelo teórico que sintetize ou integre o comportamento de escolha da criança na situação lúdica e o processo decisório do ludoterapeuta que atribui "pesos" a diferentes aspectos do comportamento da criança no processo diagnóstico. Desse modo, ganha-se na formalização e sistematização do trabalho do ludoterapeuta comportamental. 


\section{Referências}

Aristóteles (2009). Ética a Nicômaco. São Paulo, SP: Edipro.

Coelho, L. S. G. (2001) Encoprese e constipação em gêmeos: um estudo de caso em ludoterapia comportamental. Psicologia: Ciência e Profissão, 21(1), 1-13. doi:10.1590/S1414-98932001000100002

Coelho, L. S. G. (2008) Aprendizagem vicária de treino de toalete através de filme de animação: estudo de caso em ludoterapia comportamental. Psicologia: Ciência e Profissão, 28(4), 846-861. doi:10.1590/S1414-98932008000400015

Cunha, T. R. S., \& Benetti, S. P. C. (2009). Caracterização da clientela infantil numa clínica-escola de Psicologia. Boletim de Psicologia, 59(130), 117-127. Recuperado de: http://pepsic.bvsalud.org/scielo. php?pid=S0006-59432009000100010\&script=sci_arttext

Dember, W. N., \& Earl, R. W. (1957). Analysis of exploratory, manipulatory and curiosity behaviors. Psychological Review, 64(2), 91-96.

Gomes, L. S. (1998). Um estudo de caso de encoprese em ludoterapia comportamental. Psicologia: Ciência e Profissão, 18(3), 54-61. doi:10.1590/S1414-98931998000300009

Kearney, C. A. (2002). Case study of the assessment and treatment of a youth with multifunction school refusal behavior. Clinical Case Studies, 1(1), 67-80. doi:10.1177/1534650102001001006

Kearney, C. A., \& Albano, A. M. (2004). The functional profiles of school refusal behavior: diagnostic aspects. Behavior Modification, 28(1), 147-161. doi:10.1177/0145445503259263

Kearney, C. A.; Silverman, W. K. (1993). Measuring the function of school refusal behavior: The School
Refusal Assessment Scale. Journal of Clinical Child Psychology, 22(1): 85-86.

Lauand, J. (2006). Deus Ludens: o lúdico no pensamento de Tomás de Aquino e na Pedagogia Medieval. In V. A. Arantes. (Org.), Humor e alegria na educação. São Paulo, SP: Summus. pp. 31-56.

\section{Laura dos Santos Gomes Coelho}

Psicóloga graduada pela Universidade de Brasília (UnB), especialista em Psicometria (UnB) e Psicologia Clínica pelo CRP-01, Brasília-DF. Brasil.

E-mail: lauragcoelho@me.com

Endereço para envio de correspondência:

SCN Q.2 Bloco D Torre B, sala 322 - Centro

Empresarial Liberty Mall. CEP: 70712-903.

Brasília - DF. Brasil.

Recebido: 08/08/2014

Aprovado: 25/01/2016

Received 08/08/2014

Approved 01/25/2016

Recibido 08/08/2014

Aceptado 25/01/2016

\section{Agradecimentos:}

A autora agradece a Larissa Coelho pela criação do desenho utilizado na ilustração da teoria da motivação de Dember-Earl e as psicólogas Luciana Junqueira e Maria Valéria Maia Nobre Rocha Saffi.

Como citar: Coelho, L.S.G. (2016). Recusa Escolar: um Estudo de Caso em Ludoterapia Comportamental. Psicologia: Ciência e Profissão, 36(1): 234-245. doi:10.1590/1982-3703001182014

How to cite: Coelho, L.S.G. (2016). School Refusal: a Case Study in Behavioral Play Therapy. Psicologia: Ciência e Profissão, 36(1): 234-245. doi:10.1590/1982-3703001182014

Cómo citar: Coelho, L.S.G.(2016). Rechazo a la Escuela: un Estudio de Caso en Ludoterapia del Comportamiento. Psicologia: Ciência e Profissão, 36(1): 234-245. doi:10.1590/1982-3703001682014 